\title{
Hosting Capacity Distribution System Yogyakarta with Ant Lion Optimization: A Case Multiobjective
}

\author{
Riki Khomarudin ${ }^{1}$, Jimmy Trio Putra ${ }^{2}$, Ramadoni Syahputra ${ }^{3}$, Anna Nur Nazilah Chamim ${ }^{4}$ \\ ${ }^{1,3,4}$ Department of Electrical Engineering, Universitas Muhammadiyah Yogyakarta, Bantul 55183, Indonesia \\ ${ }^{2}$ Department of Electrical \& Informatics Engineering, Vocational College, Universitas Gadjah Mada, Bulaksumur 55281, Indonesia
}

\section{ARTICLE INFO}

Article history:

Received March 29, 2021

Revised April 18, 2021

Accepted April 23, 2021

\section{Keywords:}

Ants Lion Optimization;

Distributed Generation;

Radial Distribution System

\section{ABSTRACT}

Penetration of hosting capacity in radial type power distribution systems aims to increase the voltage profile on the end customer side. The more electricity customers increase, the more electricity user load growth will increase. This results in a voltage drop on the end customer side in the radial distribution system, characterized by a voltage exceeding the minimum standard operating acceptable voltage. This paper aims to provide solutions to cases in radial grid type power systems in solve voltage drops. The addition of hosting capacity for distributed renewable energy generators is one of the goals to increase the capacity of the electricity system. This research uses the Ant Lion Optimization algorithm method to try to find the optimal location and capacity of Distributed Generation in the electric power distribution system. Penetration hosting capacity injects renewable energy generation in the form of solar cells. The simulation results show that the increased voltage profile in the electric power distribution system exceeds the minimum voltage drop standard. So that in reducing power losses in the radial type network.
\end{abstract}

This work is licensed under a Creative Commons Attribution-Share Alike 4.0

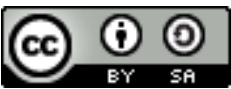

\section{Jimmy Trio Putra}

Department of Electrical Engineering and Informatics, Vocational College, Universitas Gadjah Mada, Bulaksumur 55281, Indonesia

Email: jimmytrioputra@ugm.ac.id

\section{INTRODUCTION}

The use of electrical energy every year has increased significantly. According to statistics on electricity users in the Special Region of Yogyakarta in 2014 amounted to 972,327 users, while in 2016, it increased by $1,033,966$ users. In the electric power supply system, PT. PLN uses a radial type distribution system. The radial distribution system has an advantage in its use, but the voltage fluctuations on the end of the end customer experiencing a voltage drop. For this reason, this research introduces distributed generation (DG).

Distributed Generation (DG) is the penetration of generators spread in the distribution system. The method used is hosting capacity. The purpose of hosting capacity is to improve the voltage profile [1]. The distributed generation used is distributed energy resource (DER) from photovoltaic or sunlight. This data was obtained from Queensland university photovoltaic system.

This research uses the method ant lion optimization (ALO) as an analysis of optimization methods. According to the paper [2], the ALO algorithm is inspired by the ant lion mechanism in hunting its prey. There are five hunting mechanisms such as: walking randomly, building traps, trapping in ant lion holes, ants slipping in holes, and rebuilding traps.

Distribution generation hosting capacity (DGHC) or the addition of capacity in distributed generation is an optimization technique in the power distribution system to increase the capacity of distributed generators to connect to existing distribution systems. Many problems in radial distribution systems such as voltage drops, power losses, and not cheap costs. This is the basis for achieving these main objectives. Hosting capacity and voltage are used to regulate voltage in case of overvoltage or overvoltage, and under-voltage or voltage drop. This problem often occurs in distribution systems. Usually, it is because of a voltage drop caused by the use of electricity during peak loads. 
In the end, the latest effective computational method to evaluate capacity addition is the problem of uncertainty of grid parameters and the connected multi generators being addressed [3]. Hosting capacity to find renewable energy uncertainties such as unbalanced phases is reconfigured with particle swarm optimization (PSO) [4]. The aim of the improvement approach is achieved better than the hosting capacity level, which can be used as the selection of conventional conductors under the same test conditions [5]. For the purpose framework, the effects of voltage deviation constraints, load growth, DG type, and network structure from Hosting Capacity (HC) are comprehensively studied using DG technology differences (such as from wind and photovoltaic) [6].

On the other hand, on the previous research, the control strategy for distributed integration of photovoltaic (PV) and battery energy storage system in microgrid, reactive power optimization of distributed generation for voltage regulation of distribution systems, and reconfiguration of distribution network with DG using fuzzy multi-objective method has been investigated by [7][8]. Other than that, high PV penetration impact on European-based low voltage (LV) residential network has been researched by [9]. Besides that, load flowbased voltage strategy indices for voltage stability and contingency analysis for optimal location of Static Synchronous Compensator (STATCOM) in distribution network with the integrated distribution unit has also been investigated by [10]. Thus, creating a gap between research in the West (Europe) and East (Asia) relating to hosting capacity, especially PV and the other resource of renewable DG (for instance: wind turbine) in the real LV system in Indonesia, more specifically in Yogyakarta that has never been studied before. In this study, we propose a study regarding a multi-objective case about hosting a Yogyakarta capacity distribution system with Ant Lion Optimization (ALO).

In increasing photovoltaic as hosting capacity in real systems, methods can be used by equipment to improve management of low voltage systems with high PV penetration [11]. HC is used to find out how much DG capacity can be connected, so a separate grid technique is used with the Monte Carlo method. Hosting capacity to find out how many electric vehicles in charging can be accommodated on the distribution network [12]. HC is used to find out how much DG capacity can be connected, so a separate grid technique is used with the Monte Carlo method. Hosting capacity to find out how many electric vehicles in charging can be accommodated on the distribution network [13]. The purpose of the research in [14] is to determine the hosting capacity of the wind turbine of the control algorithm in the distribution system that can be easily applied in the existing distribution network. On the other hand, the following research also implemented ALO [15].

This research using the Ant Lion Optimization (ALO) method can be proven to be used in optimizing the optimal placement of Distributed Generation (DG). The resulting indicators such as increasing the voltage profile, reducing power losses, and determining objective functions such as the ENS cost, the development of the load line index (LLI). The Ant Lion Optimization (ALO) approach also has similar results when compared to other methods such as Genetic Algorithm (GA), Flower Pollination Algorithm (FPA), and Particle Swarm Optimization (PSO). Furthermore, the next section will be discussed related to research methods to further discuss how to examine the load flow, hosting capacity distribution system with ALO, constraints, and objective functions.

\section{RESEARCH METHOD}

Backward sweep starts from the furthest end of the network, the load current at the load point. Therefore, the current flowing in the channel is calculated according to the assumption or calculation of the voltage in the previous iteration. After calculating the current flowing in the channel, at the backward sweep, starting from the source point, the voltage from each bus point is updated. After the forward sweep, current injection compensation is calculated. Then the convergence criteria are adjusted to the point of voltage, load or line current, and input power to the network [16].

\subsection{Backward Sweep}

In this iteration, the voltage from all points is assumed to be the same as the voltage at the main source. If there are multiple sources on the network, the compensation injection current at this source is valued zero at the first iteration. On the other hand, the voltage at each point and injection current ratio is calculated in the previous iteration. When each injection point and current is known, the current can be searched by [16]

$$
I_{l d i}=\left[\frac{P i+J Q i}{V i}\right]
$$

where $I_{l d i}$ is loading current in point $I, P_{i}$ is active power requirements at a point $I, Q i$ is reactive power requirements at the point $I, V_{i}$ is the voltage at the point $i$. 


\subsection{Forward Sweep}

In forward sweep analysis, starting from the main source point where the voltage value is known, the impedance and current flowing in each channel are known, all the updated point voltages ignore other sources. Equation (2) is used to find the voltage and the know compensation injection current. If the compensated injection current is zero in the first iteration, the voltage at each point and the compensated injection current are calculated in the previous iteration. This is formulated as [16]

$$
V_{i}=V_{v i}-\left(Z_{i} \times I_{L i}\right)
$$

where, $i$ is $I, \ldots, N, V_{i}$ is the voltage at a point $i, V_{v i}$ is the voltage at the top of point $i, Z_{i}$ is the impedance of channel $i, I_{L i}$ is current lowing in channel $i$.

\subsection{Ant Lion Optimization Algorithm}

Ant Lion Optimization (ALO) is inspired by nature with an algorithm created by Seyedali Mirjalili in 2015. The ALO algorithm mimics the hunting mechanism of ant lions in nature. According to [17][18], there are six main rounds for hunting to kill prey, such as channel $i$ :

1. Ant Run Randomly

Ants that walk randomly can be formulated as

$$
X_{(t)}=\left[0, \operatorname{cumsum}\left(2_{r(t 1)-1}\right), \operatorname{cumsum}\left(2_{r(t 2)-1}\right), \ldots,\left(2_{r(t n)-1}\right)\right]
$$

where cumsum is a cumulative calculation of sum, $n$ is a maximum number of iterations, $t$ is steps of random travel such as

$$
r(t)=\left\{\begin{array}{l}
1 \text { if } \text { rand }>0.5 \\
0 \text { if } \text { rand }<0.5
\end{array}\right.
$$

where, rand is a number generator between $[0,1]$. A random walk can be made to enter into the search space can be written as

$$
X_{i}^{t}=\frac{\left(X_{i}^{t}-a_{i}\right) x\left(d_{i}^{t}-c_{i}^{t}\right)}{\left(b_{i}-a_{i}\right)}+c_{i}^{t}
$$

where $a_{i}$ is the minimum value of the random walk of the variable, $b_{i}$ is the maximum value of the random walk of the variable $i_{t h}, C_{i}^{t}$ is the minimum value of the ith variable in $i_{t h}$ iteration, $d_{i}^{t}$ is the maximum value of the variable $i_{t h}$ in the $t_{t h}$ iteration. The location of the ants depends on the compatibility of the given matrix function such as

$$
\begin{aligned}
M_{\text {ant }} & =\left(\begin{array}{ccccc}
A_{1.1} & A_{1.2} & \ldots & \ldots & A_{1 . d} \\
A_{2.1} & A_{2.2} & \ldots & \ldots & A_{2 . d} \\
\vdots & : & : & : & : \\
A_{n .1} & A_{n .2} & \ldots & \ldots & A_{n . d}
\end{array}\right) \\
M_{\text {ant }} & =\left[\begin{array}{lllll}
f\left(\left[A_{11}\right.\right. & A_{12} & \ldots & \ldots & \left.A_{1 d}\right) \\
f\left(\left[\begin{array}{lllll}
A_{21} & A_{22} & \ldots & \ldots & A_{2 d}
\end{array}\right)\right. \\
\vdots \\
f\left(\left[\begin{array}{lllll}
A_{n 1} & A_{n 2} & \ldots & \ldots & \left.A_{n d}\right)
\end{array}\right]\right.
\end{array}\right.
\end{aligned}
$$

where MOA is the matrix displays matching values from the ant's matrix location MANT. If ants and antlions are hiding in the search room, then the corresponding location and matching matrix is given as

$$
\begin{gathered}
M_{\text {ant lion }}=\left(\begin{array}{ccccc}
A_{1,1} & A_{1,2} & \ldots & \ldots & A_{1, d} \\
A_{2,1} & A_{2,2} & \ldots & \ldots & A_{2, d} \\
\vdots & \vdots & : & : & : \\
A_{n, 1} & A_{n, 2} & \ldots & \ldots & A_{n, d}
\end{array}\right) \\
M_{O A L}=\left[\begin{array}{ccccc}
f\left(\left[A_{11}\right.\right. & A_{12} & \ldots & \ldots & \left.A_{1 d}\right) \\
f\left(\left[A_{21}\right.\right. & A_{22} & \ldots & \ldots & \left.A_{2 d}\right) \\
& \vdots & & & \\
f\left(\left[A_{n 1}\right.\right. & A_{n 2} & \ldots & \ldots & \left.A_{n d}\right)
\end{array}\right]
\end{gathered}
$$

where $\mathrm{M}_{\mathrm{OAL}}$ is a matrix that displays matching values from the location of the ant lion. In the real depiction, it can be seen in Fig. 1. 


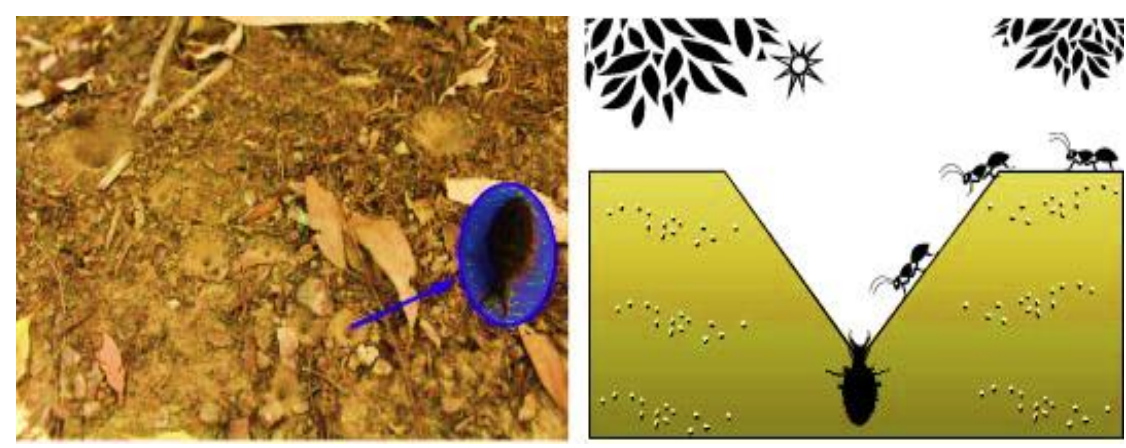

Fig. 1. Ants Walk Randomly

2. Build Traps

Building Traps to get a higher probability of capturing ants, a roulette wheel is used. This mechanism identifies the most suitable ant lion [19]. For more details, it can be seen in Fig. 2.

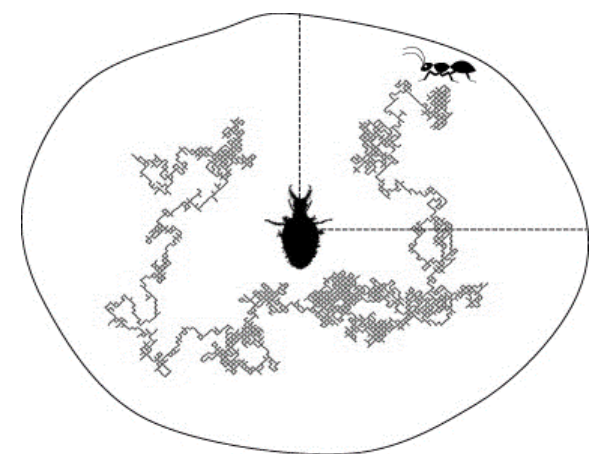

Fig. 2. Ants Build Traps

3. Trapped in an ant lion anethole

The mathematical equation for trapping ants is given according to the following equation

$$
\begin{aligned}
& c_{i}^{t}=\text { Ant lions }_{t}^{t}+c^{t} \\
& d_{i}^{t}=\text { Ant lions }_{t}^{t}+d^{t}
\end{aligned}
$$

where, $c_{i}^{t}$ is the minimum value of all variables at ith iteration, $d_{i}^{t}$ is the maximum value of all variable on ith iteration, $c^{t}$ is the minimum value of all variables for $i t h$ ant, $d^{t}$ is the maximum value of all variables for ith ant.

4. The ants slip towards the ant lion

To move the ants toward the ant lion, the ant lion shoots sand out. Mathematically, it can be modeled as

$$
\begin{aligned}
& C^{t}=\frac{c^{t}}{I} \\
& D^{t}=\frac{d^{t}}{I}
\end{aligned}
$$

where $I$ is $10^{\omega} \frac{t}{T}$, $t$ is the current iteration, $T$ is the maximum of iteration numbers.

5. Catch prey and rebuild the hole

The last stage of the hunting behavior of an ant lion is to catch an ant that reaches the bottom of the pit and then return to renew the position from the last position by

$$
\text { Ant } \text { lion }_{j}^{t}=A n t_{i}^{t} \quad \text { if } f\left(A n t_{i}^{t}\right)>f\left(\text { Ant } \text { lion }_{j}^{t}\right)
$$

6. Elitism

The most important thing about the evolution of algorithms is finding the best main solution. This can be modeled by

Hosting Capacity Distribution System Yogyakarta with Ant Lion Optimization: A Case Multiobjective (Riki 


$$
\begin{gathered}
A n t_{i}^{t}=\frac{R_{A}^{t}+R_{E}^{t}}{2} \\
\text { populasi }=\left(d g_{\text {max }}-d g_{\text {min }}\right) x \operatorname{rand}()+d g_{\text {min }}
\end{gathered}
$$

where, $R_{A}^{t}, R_{E}^{t}$ is walk randomly around ant lions with roulette wheels

7. Constraints

a. Constrains Power Balance

The balance of power as a limiting function can be formulated by [1]

$$
P+\sum_{k=1}^{N} P_{D G}=P_{d}+P_{\text {loss }}
$$

where $P_{\text {loss }}$ is active power loss, $P_{D G}$ is the DG Capacity.

\section{b. DG Capacity Constraints}

The optimization results must also meet the availability of DG capacity limits by the standard capacity intermittency. However, in [1], the DG capacity limits are stated as

$$
40<P_{D G}<168,000
$$

where the value of the photovoltaic DG capacity limit is when the maximum power is generated. The DG data is generated based on real-time monitoring from the Queensland university photovoltaic.

8. Multi-Objective Function

a. Minimize Power Losses

In minimizing the power loss due to voltage drop, it can be formulated as

$$
P_{\text {loss }}=\sum_{i}^{n} I_{i}^{2} R^{2}
$$

where $P_{\text {loss }}$ is active power loss, $I_{i}^{2}$ is the amount of network flow, $R^{2}$ is the magnitude of distribution network resistance.

b. Cost of energy not Supply

In this condition, DG can be used to return power to the interference branch distribution section and increase the reliability of the distribution system. So, the distributed generator system is optimally implemented to reduce the cost of the distribution system in customer damage. In this study, reliability is modeled in the CENS of the distribution system [19]. Cost of energy not supplied (CENS) defined as

$$
C_{D G}^{E N S}=\sum_{i=1}^{N b r a c h} x \sum_{j=1}^{N 1} x \lambda_{i} x L_{i} x \rho_{0}^{i n t} x\left(\frac{1+\operatorname{InfR} R}{1+\operatorname{IntR}}\right)^{i-1} x t_{i} x D_{j}
$$

where, $C_{D G}^{E N S}$ is energy costs not supplied/year, $N_{l}$ is number of grid branches, $L_{i}$ is distribution system length branch length distribution system branch, $t_{i}$ is the time taken for the change of interference, $C_{D G}^{E N S}$ is energy costs that were not supplied in the first year, $\lambda_{i}$ is the rate or rapid failure of the branch. The variable, $\lambda_{i}$ is $\frac{\text { the amount of interference during a certain time interval }}{\text { the amount of time-lapse of observation }}$ and the variable $D_{j}$ is load requests at the point $j$.

c. Reducing the cost of using DG

The cost of using DG is included in the investment $C_{D G}^{I n v s}$ ), operation $C_{D G}^{O p e r}$ ) and maintenance costs $\left.C_{D G}^{M a i n}\right)$. The cost of using DG can be defined with $C_{D G}^{I n v s}(\$ / \mathrm{MWh}$ ) will be paid in advance, and it is related to the purchase and installation of each DG [19]. It can be calculated with 


$$
C_{D G}^{I n v s}=\sum_{i=1}^{N d g} C_{i}^{\text {invest }}
$$

where, $C_{i}^{\text {invest }}$ is purchase and installation costs from i-th DG units. $C_{D G}^{\text {Main }}$ in (\$/MWh) is an annual fee that displays interest rates and rate increases and can be modeled as [19]

$$
C_{D G}^{M a i n}=\sum_{i=1}^{N d g} C_{i}^{m t n}
$$

where, $C_{i}^{m t n}$ is maintenance costs from $\mathrm{i}_{\mathrm{th}}$ DG and can be calculated as

$$
C_{i}^{m t n}=C_{0}^{m t n} x\left(\frac{1+\operatorname{InfR}}{1+\operatorname{IntR}}\right)^{i-1}
$$

where, $C_{0}^{m t n}$ is initial maintenance costs (value $=0$ ).

d. Load Line Index

Load Line Index (LLI) an index of the possibility of increasing the burden in the future. According to [20], growth in the number of channel loads every year around $1 \%$. So, in this study, by testing the IEEE Standard Radial Distribution type system can find out the development of loads bus for the next 20 years. Load Line Index (LLI) can be formulated as

$$
L_{i}=L_{o} x\left(1+L_{\text {growth }}\right)^{i-1}
$$

where $L_{i}$ (Load Increment) is a large increase in busload, $L_{o}$ is expensed during the first year, $L_{\text {growth }}$ is load growth every year.

e. Multi-Objective

The main multi-objective function of this study case is equal with several loss reduction functions, energy not supplied function, DG investment function, and Load Line Index $\left(L_{i}\right)$. It can be written as

$$
O F=P_{\text {loss }}+C_{D G}^{E N S}+C_{D G}^{I n v s}+C_{D G}^{M a i n}+L_{i}
$$

where, $O F$ is the objective function, $P_{\text {loss }}$ is the amount of power loss, $C_{D G}^{E N S}$ is energy costs that are not supplied, $C_{D G}^{I n v s}$ is investment costs, $C_{D G}^{\text {Main }}$ is maintenance costs, $L_{i}$ is bus load growth for the coming 20 years.

\subsection{Flowchart of this Research}

The Steps in Distributed Generation are using Ant Lion Optimization based on Fig. 3. It can be explained as follow. Start - The first step is creating a simulation program. Initialization - The second step is an initialization, which is used to introduce parameters or what is commonly called a header. Initialization must have value because the initial program will be called a programmable function. Load flow code - The baseload flow program is used to read the distribution system created. This program is to determine the value of buses and branches in the distribution system. The data want to look for on the bus are active power(P) and reactive power (Q) to find out the feeder load profile. ALO code - The ant lion optimization (ALO) program can be explained in simple terms as follows: reads all feeder and load data in the destination distribution system. Then, find the best DG location by random method on the roulette wheel. Initialize position/solution and maximum looping $=100$, with minimum DG capacity $=40 \mathrm{kWP}$ and maximum capacity $=16800 \mathrm{kWp}$. Then get a convergence curve or fitness curve in the objective function of minimizing power losses. Constraint - The constraint function to determine the level of repair voltage profile of at least $0.92 \mathrm{PU}$ and a maximum of 1.05 PU. Objective function - This objective function serves to determine the direction of the intended simulation results. This function is to reduce the power loss resulting from the addition of a new DG.

\section{RESULTS AND DISCUSSION}

Ant Lion Optimization algorithm (ALO) can be applied to DG penetration optimization techniques with Hosting Capacity theory. The research conducted 3 case studies. The first section is a comparison with other methods. The next is case study 1 and case study 2 . This study uses the IEEE standard radial distribution system and the real distribution system from the Bantul substation. 


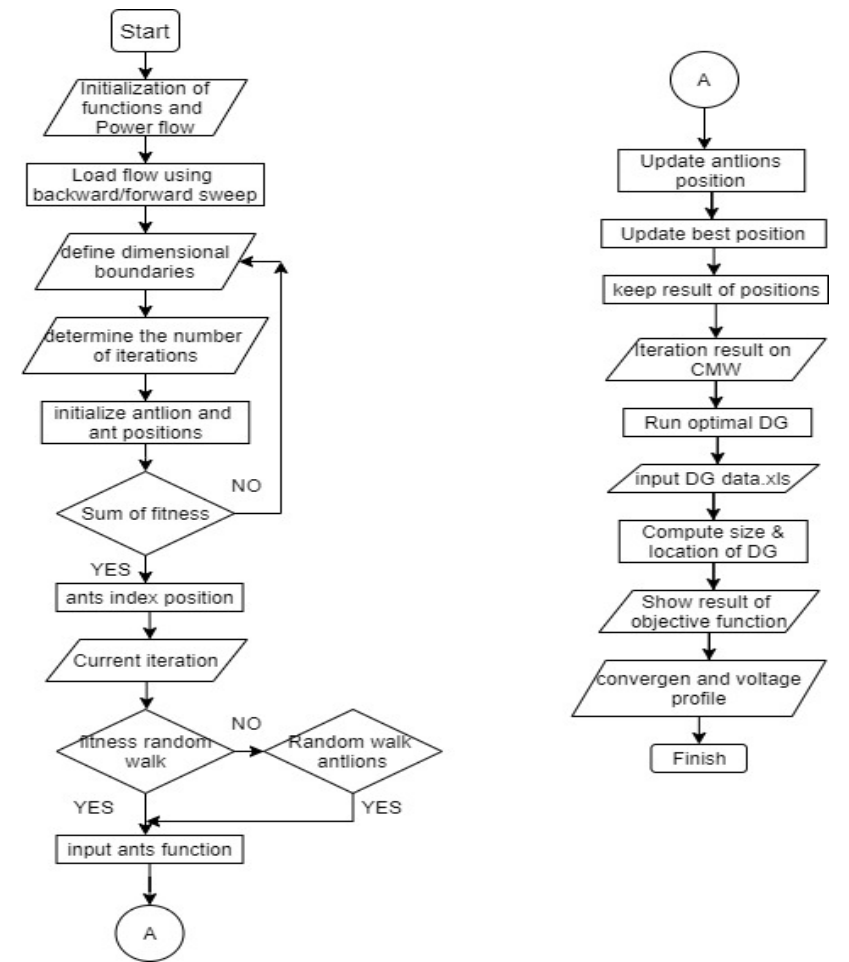

Fig. 3. Flowchart Hosting Capacity using Ant Lion Optimization

\subsection{Compare other Methods}

This is a study to compare another simulation method for optimal distributed generation, as we can show in Table 1. From the results obtained from the simulation, that the value of the reduction in power losses in the Ant Lion Optimization method $\pm 0.8 \mathrm{~kW}$. This can be compared with other methods such as FPA, GA, PSO with competitive convergence value. So, the Ant Lion Optimization (ALO) method also has a good convergence for the function of reducing power losses with a single Distributed Generation. In [21], represented some references about the genetic algorithm and particle swarm optimization for optimal distributed generation. Based on the results of the comparison, the Ant Lion Optimization approach method can be applied in the optimization of the optimal determination of Distributed Generation (DG).

Table 1. Review Related Optimal DG in Case IEEE 33-bus Test System

\begin{tabular}{cccc}
\hline Methods & DG location & DG size $(\mathbf{k W})$ & $\begin{array}{c}\text { Losses } \\
(\mathbf{k W})\end{array}$ \\
\hline Ant Lion Optimization & 6 & 2554.23 & \pm 0.8 \\
Flower Pollination Algorithm & 6 & 2588.7 & 0.2 \\
Genetic Algorithm & 11 & 1.5 & 0.1063 \\
Particle Swarm Optimization & 8 & 1.1768 & 0.1053 \\
\hline
\end{tabular}

\subsection{Case Study 1}

This section uses the IEEE 33-bus standard test system in Fig. 4 that is modeling radial type networks according to the IEEE standard. From the data result, the IEEE 33-bus is used as an experimental simulation before using real data on a radial distribution system. Network data and connected load data based on the IEEE standard are used in data analysis without changing the form and data structure that is in the IEEE 33-bus.

The results of the value profile voltage before the addition of DG and after the presence of DG are shown in Fig. 5. One of the objectives of the optimization carried out in this study is to increase the stress profile. The simulation results carried out on the IEE 33-bus standard radial system shows good results in increasing the voltage profile using the Ant Lion Optimization method. As in Fig. 5, the green indicator shows the voltage profile before being given Distributed Generation (DG), while the blue indicator results after being affected by single Distributed Generation (DG) penetration. The increase in the voltage profile is shown on bus 18 with a value of $0.968 \mathrm{PU}$, which can be increased to $0.987 \mathrm{PU}$ so that the results obtained to meet the standard in customer voltage distribution. 


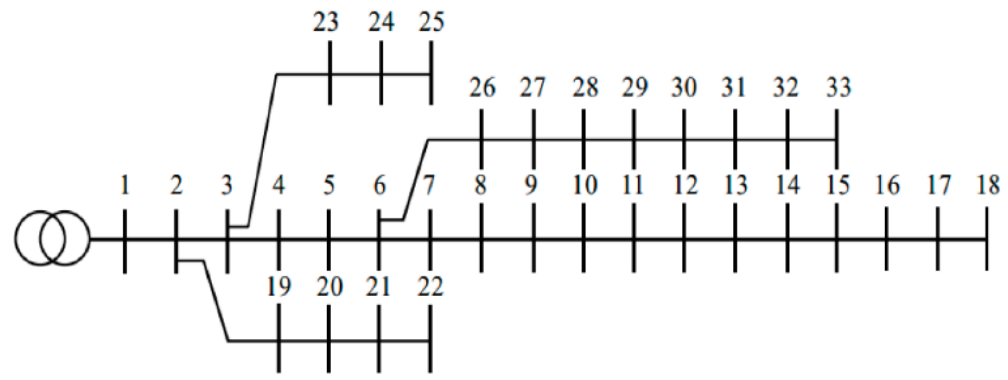

Fig. 4. The 33-bus Network Structure

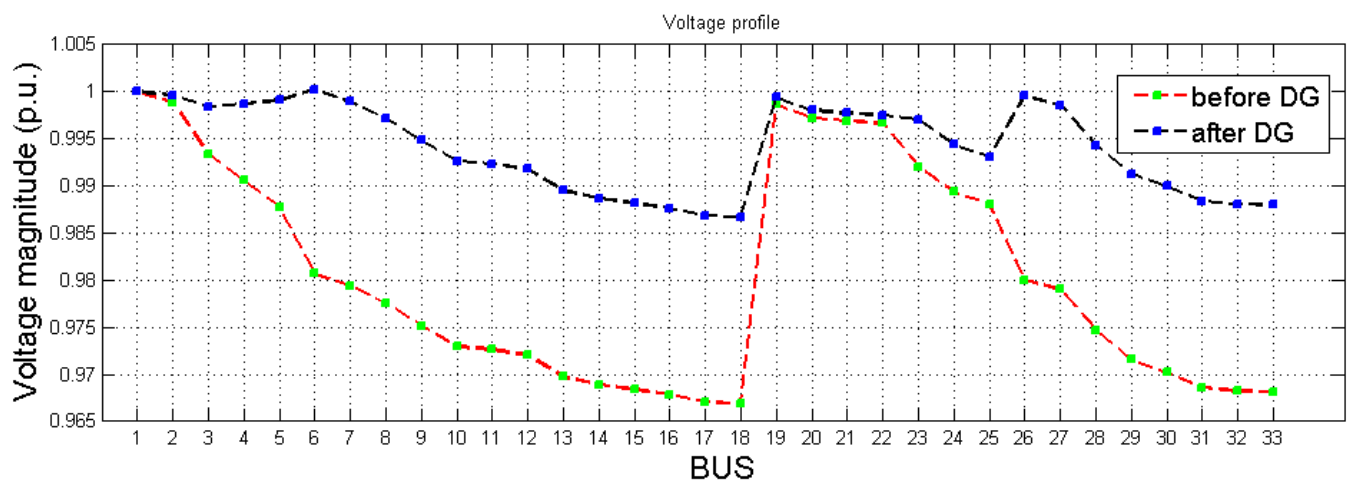

Fig. 5. The 33-bus Voltage Profile Value

The consistent curve in Fig. 6 is the suitability curve shown for the Ant Lion Optimization simulation results. Convergent is shown to achieve the objective function of reducing power losses in the system. Besides that, the objective function is also displayed in Fig. 6. The iteration results show that it is $0.02 \mathrm{~kW}$ at the time of the 12th iteration and converging. Because of that, it is known that the convergence characteristics of the Ant Lion Optimization Algorithm can show the iteration results that do not take long to reach convergence. The indicator of success in reducing is shown from the y-axis as a function of the amount of power loss and the $\mathrm{x}$-axis by the number of iterations carried out until it reaches convergence.

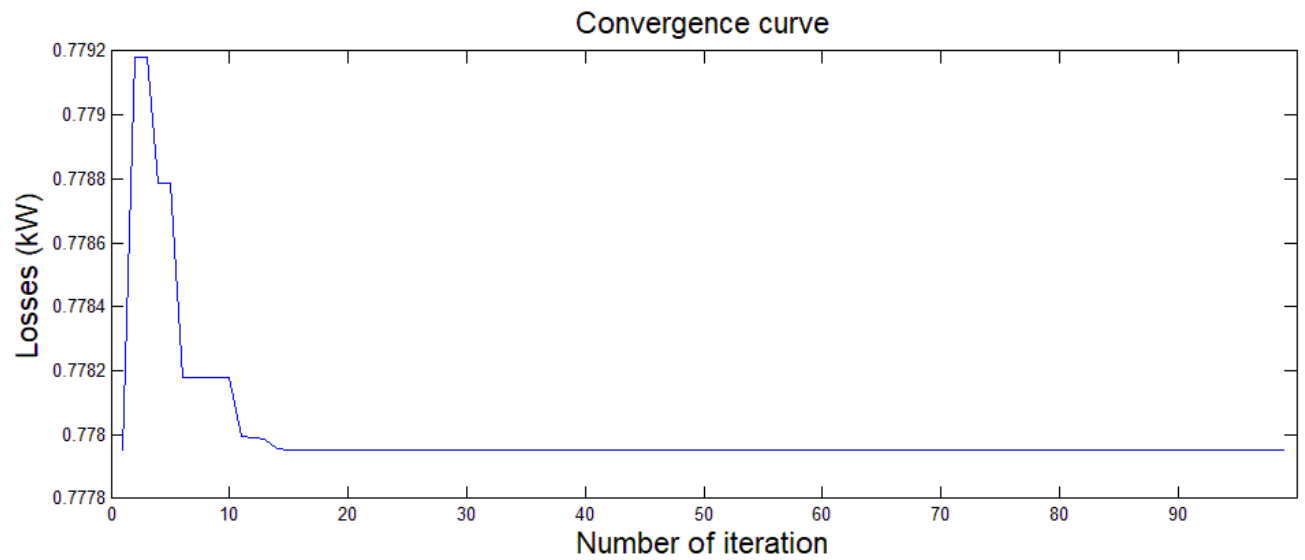

Fig. 6. Losses Optimization Convergence Curve

This part is discussing losses in each bus in the IEEE 33-bus feeder by optimization. Fig. 7 represented active and reactive losses in each bus element. It shows that power losses have a large power loss value, and it will affect the voltage profile. The value of active and reactive power losses is high due to the long distance at the initial bus position of the line, where the power loss value is obtained by (16). 


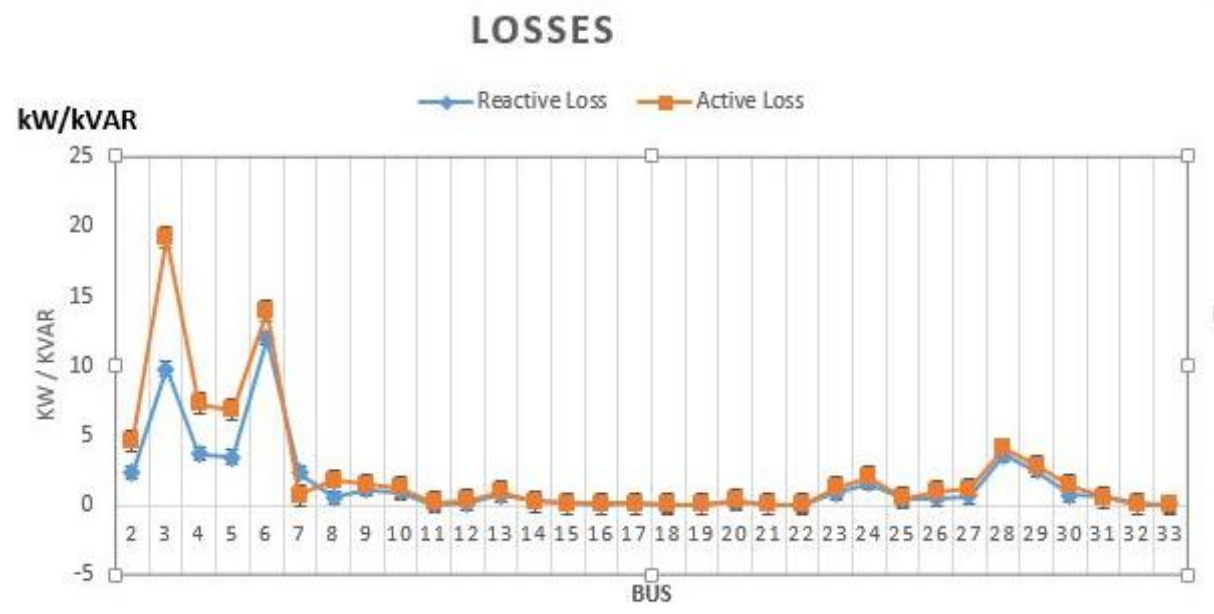

Fig. 7. Losses each of Bus

\subsection{Case Study 2}

Case study 4 is used as the implementation of a real distribution system. The Data were taken from PT. PLN Unit Pelayanan Pelanggan (PU3) in Bantul Substation. This substation has a capacity of 3051.93 MVA with a high voltage of $150 \mathrm{kV}$. This step-down transformer converts the $150 \mathrm{kV}$ to $20 \mathrm{kV}$ voltage which is used as a distribution system to load centers. This study uses data feeder 11 as a whole or the output of the stepdown transformer three feeder section five. The voltage profile value observed in this study is a distribution system of $20 \mathrm{kV}$. This $20 \mathrm{kV}$ value is considered as the database for the analysis of the maximum voltage profile of 1 PU (Per Unit). Fig. 8 represents a feeder distribution system for radial type.

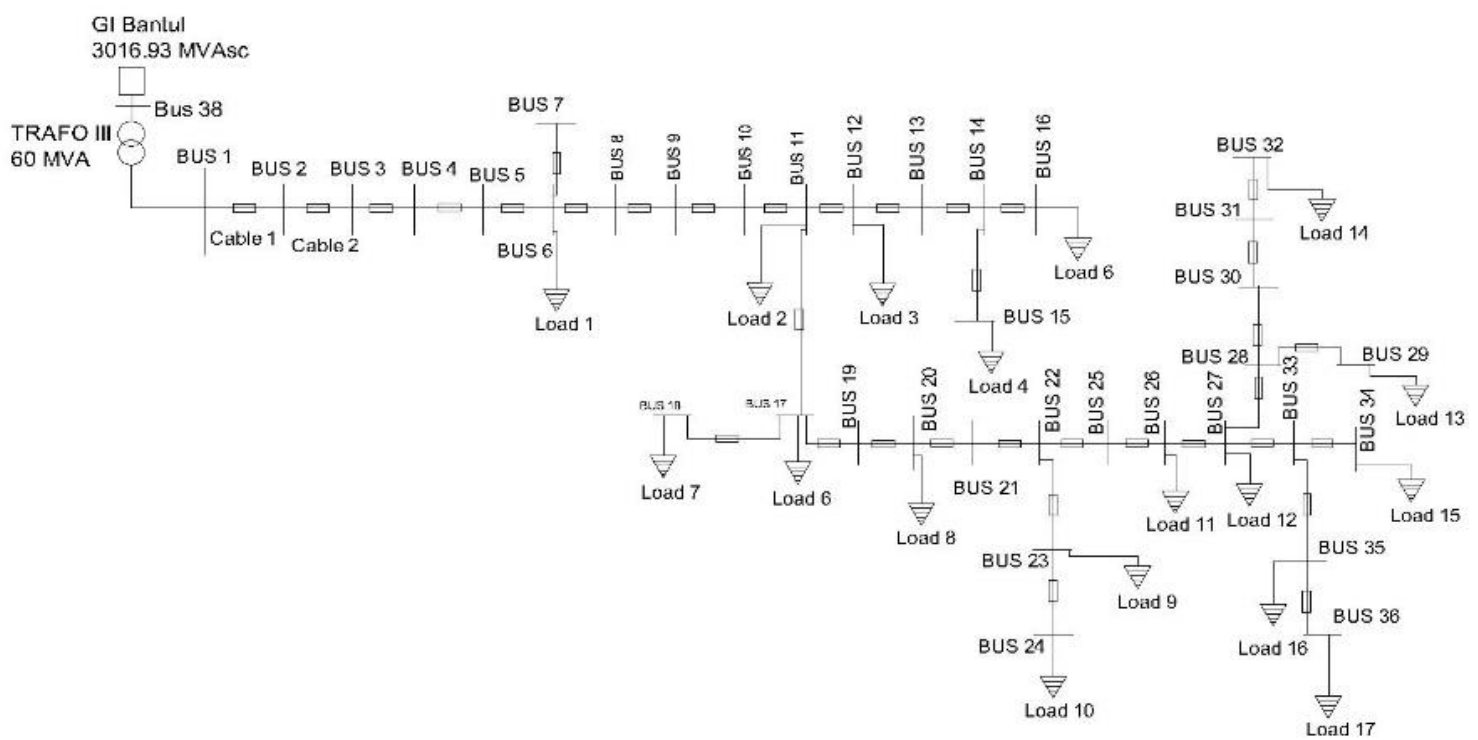

Fig. 8. Single Line Diagram in a Radial Distribution System

The simulation results conducted that the optimal placement of DG on bus 17. On bus-17, which has not added DG, the voltage value is $0.92 \mathrm{PU}$, and it is followed by a decreased bus voltage value. Then after additional the optimal DG placement with the addition of the 17 bus, the voltage correction value on bus 17 is 0.97 PU. In the addition of 1 DG, the value of the voltage on the bus 26 to 36 is still 0.957 PU. It can show in Fig. 9. The objective function is calculated based on (15) to minimize power loss. The results of this simulation show that the value of power losses can be minimized when starting the first ten iterations. The highest power loss value is $4.88 \mathrm{~kW}$, then it can be minimized to $4.66 \mathrm{~kW}$ during the 10 th iterations. It can be shown in Fig. 10 and Fig. 11. 


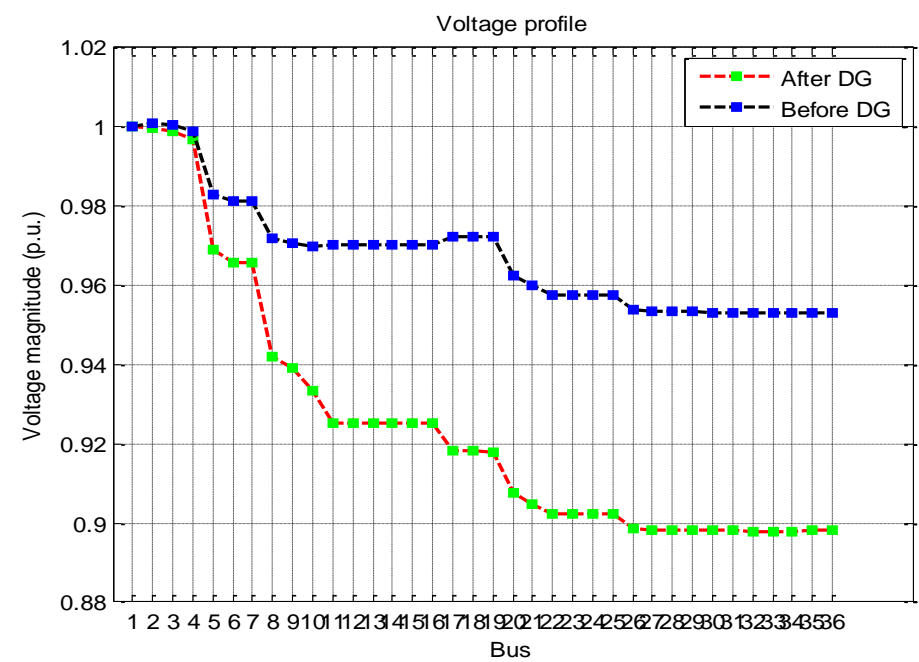

Fig. 9. Voltage Profile Yogyakarta, Bantul Substation

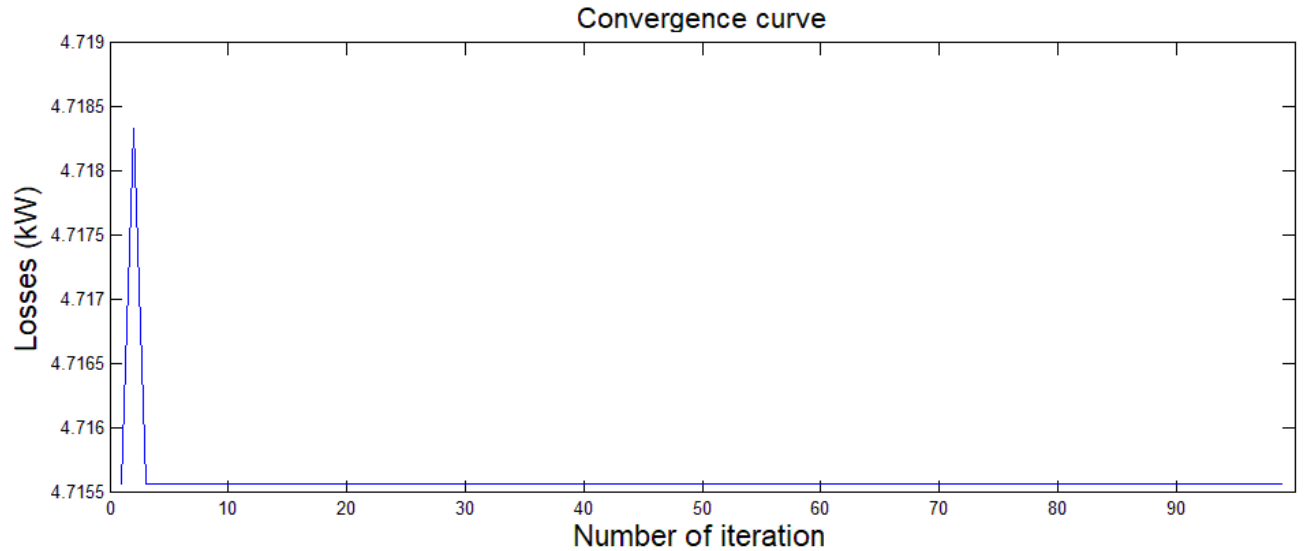

Fig. 10. Losses Optimization

\section{LOSSES}

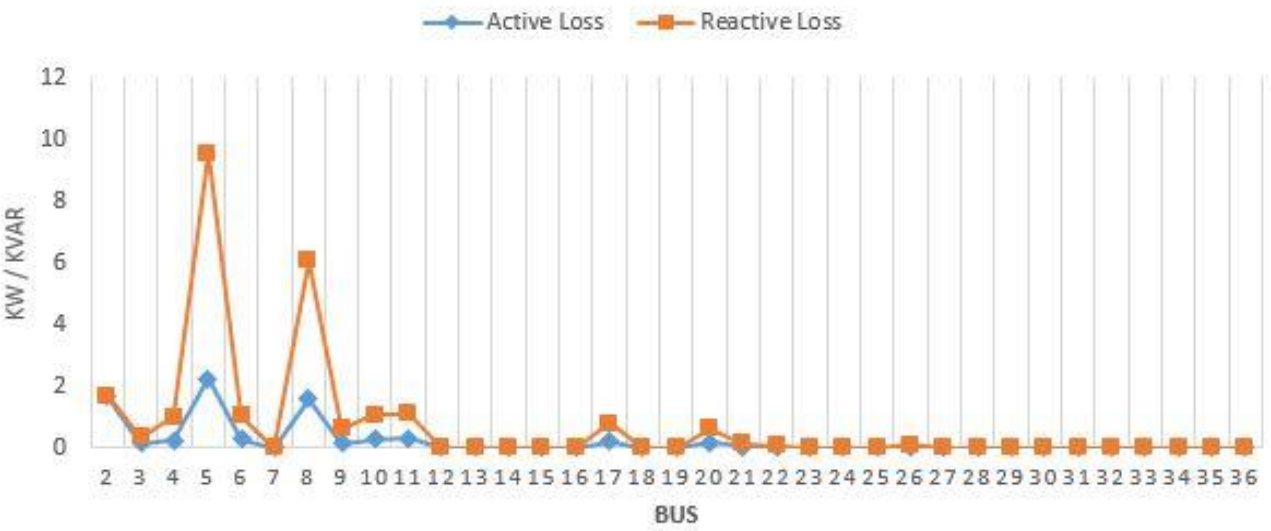

Fig. 11. Losses in each of Bus

We know that the ant lion algorithm can use for looking optimal placement of distributed generation hosting capacity for radial distribution networks. In Table 2, we can show ten simulations, and the result gets optimal location and capacity constantly. 
Table 2. Optimal Capacity and Location for Yogyakarta Distribution Network in 10 Simulation Algorithm

\begin{tabular}{cccccc}
\hline No & Iteration & Ant Lion Optimization & DG location & DG size (kWp) & Reduction loses (kW) \\
\hline $\mathbf{1}$ & 1 & 99 & 17 & 3110.63 & 0.108 \\
$\mathbf{2 .}$ & 2 & 99 & 17 & 3110.63 & 0.108 \\
$\mathbf{3 .}$ & 3 & 99 & 17 & 3110.63 & 0.101 \\
$\mathbf{4 .}$ & 4 & 99 & 17 & 3110.63 & 0.10 \\
$\mathbf{5 .}$ & 5 & 99 & 17 & 3110.63 & 0.03 \\
$\mathbf{6 .}$ & 6 & 99 & 17 & 3110.63 & 0.01 \\
$\mathbf{7 .}$ & 7 & 99 & 17 & 3110.63 & 0.03 \\
$\mathbf{8 .}$ & 8 & 99 & 17 & 3110.63 & 0.05 \\
$\mathbf{9 .}$ & 9 & 99 & 17 & 3110.63 & 0.02 \\
$\mathbf{1 0}$ & 10 & 99 & 17 & 3110.63 & 0.08 \\
\hline \multicolumn{6}{r}{}
\end{tabular}

The results obtained in Table 3 are the comparisons of the results for the application of the Ant Lion Optimization method to the IEEE standard distribution system. From Table 3, it is found that the results can increase the lower voltage profile index increases properly. Because of that, we can reduce power losses for convergent values. The results obtained for the Distributed Generation capacity in a long radial system require a large capacity to increase the minimum voltage profile. The 33-bus puts DG on bus 6 with a capacity of $2554.23 \mathrm{kWp}$, on the 69 -bus distributed system on bus 61 with a capacity of $1889.65 \mathrm{kWp}$, and on the 85 -bus radial, the system is placed on bus 8 with a capacity of $13760.87 \mathrm{kWp}$. One of the objective functions used is the development of busloads for the next 20 years.

Table 3. Test Results of the IEEE Standard System

\begin{tabular}{cccc}
\hline Parameters & 33 bus & 69 bus & 85 bus \\
\hline Power Factor & 0.85 & 0.85 & 0.85 \\
\hline Optimal Bus & 6 & 61 & 8 \\
\hline DG Capacity $(k W p)$ & $2,554.23$ & $1,898.65$ & $13,760.87$ \\
\hline$\Delta$ Power Loss (kW) & 0.05 & 1.4 & 0.6 \\
\hline $\boldsymbol{V}_{\min }$ p.u. with DG & 0.986 & 0.989 & 0.97 \\
\hline $\boldsymbol{V}_{\min }$ p.u. without DG & 0.968 & 0.965 & 0.88 \\
\hline $\boldsymbol{V}_{\max }$ p.u. with DG & 1 & 1 & 1.01 \\
\hline Addition of Load Bus & $39-$ bus & $83-$ bus & 1.1176 \\
\hline Load Line Index (LLI) & 1.1818 & 1.2028 & \\
\hline
\end{tabular}

\section{CONCLUSION}

In this study, the authors can conclude as follow. From the 33-bus system testing, the optimal DG capacity is $2554.23 \mathrm{kWp}$ with a location on bus 6. In the 69-bus system test, the optimal DG capacity is $1898.65 \mathrm{kWp}$ with the location on bus 61 . At the 85 -bus system testing, the capacity The optimal DG is $13760.87 \mathrm{kWp}$ with location on bus 8 . In testing the real system on feeder 5, Bantul Substation obtained an optimal DG capacity of 3110.63 with bus location 17. Adding DG to the 33-bus system can increase the voltage profile from a minimum voltage of $0.968 \mathrm{PU}$ to $0.986 \mathrm{PU}$. Adding DG to the 69-bus system can increase from a minimum Voltage of 0.965 PU to be 0.989 PU. The 85 -bus system can raise the voltage profile after adding DG from a minimum voltage of 0.88 PU. to 0.97 PU. In testing the feeder 5 Bantul substation after adding DG can increase the voltage profile from 0.92 PU. to 0.97 PU. Ant Lion Optimization Algorithm can be applied to the multiobjective function. The objective functions are optimal Distributed Generation(DG) location and capacity, Optimum losses, ENS value, and load line index (LLI). Ant lion optimization can also enhancement voltage value with a constraint minimum of $0.96 \mathrm{PU}$ and a maximum of $1.05 \mathrm{PU}$.

\section{REFERENCES}

[1] M. R. Ali, "Optimasi Penempatan Dan Kapasitas Distributed Generation Dengan Metode Flower Pollination Algorithm," Thesis Universitas Gadjah Mada, 2015.

[2] S. Mirjalili, "The ant lion optimizer," Adv. Eng. Softw., vol. 83, pp. 80-98, 2015. https://doi.org/10.1016/j.advengsoft.2015.01.010

[3] S. Mina Mirbagheri, D. Falabretti, V. Ilea, and M. Merlo, "Hosting Capacity Analysis: A Review and a New Evaluation Method in Case of Parameters Uncertainty and Multi-Generator," Proc. - 2018 IEEE Int. Conf. Environ. 
Electr. Eng. 2018 IEEE Ind. Commer. Power Syst. Eur. EEEIC/I CPS Eur. 2018, pp. 1-6, 2018. https://doi.org/10.1109/EEEIC.2018.8494572

[4] Y. Y. Fu and H. D. Chiang, "Toward optimal multi-period network reconfiguration for increasing the hosting capacity of distribution networks," IEEE Power Energy Soc. Gen. Meet., vol. 2018-Janua, no. 5, pp. 1-5, 2018. https://doi.org/10.1109/PESGM.2017.8274614

[5] S. M. Ismael, S. H. E. Abdel Aleem, A. Y. Abdelaziz, and A. F. Zobaa, "Practical Considerations for Optimal Conductor Reinforcement and Hosting Capacity Enhancement in Radial Distribution Systems," IEEE Access, vol. 6, pp. 27268-27277, 2018. https://doi.org/10.1109/ACCESS.2018.2835165

[6] M. S. S. Abad, J. Ma, D. Zhang, A. S. Ahmadyar, and H. Marzooghi, "Probabilistic Assessment of Hosting Capacity in Radial Distribution Systems," IEEE Trans. Sustain. Energy, vol. 9, no. 4, pp. 1935-1947, 2018. https://doi.org/10.1109/TSTE.2018.2819201

[7] A. Khamis, M. R. A. Ghani, G. C. Kim, M. S. M. Aras, M. A. Bin Zabide, and T. Sutikno, "Control strategy for distributed integration of photovoltaic and battery energy storage system in micro-grids," Telkomnika (Telecommunication Comput. Electron. Control., vol. 16, no. 5, pp. 2415-2427, 2018. https://doi.org/10.12928/telkomnika.v16i5.10249

[8] J. T. Putra and Sarjiya, "Reactive power optimization of distributed generation for voltage regulation of distribution systems," Proc. 2016 8th Int. Conf. Inf. Technol. Electr. Eng. Empower. Technol. Better Futur. ICITEE 2016, vol. 2, no. 1, 2017. https://doi.org/10.1109/ICITEED.2016.7863288

[9] K. A. Baharin, N. A. Isa, C. K. Gan, and M. Shamshiri, "High PV penetration impact on European-based LV residential network," Telkomnika (Telecommunication Comput. Electron. Control., vol. 16, no. 4, pp. 1375-1382, 2018. https://doi.org/10.12928/telkomnika.v16i4.9056

[10] I. Alhamrouni, M. A. Alif, B. Ismail, M. Salem, A. Jusoh, and T. Sutikno, "Load flow based voltage stability indices for voltage stability and contingency analysis for optimal location of STATCOM in distribution network with integrated distributed generation unit," Telkomnika (Telecommunication Comput. Electron. Control., vol. 16, no. 5, pp. 2302-2315, 2018. https://doi.org/10.12928/telkomnika.v16i5.10577

[11] R. Torquato, D. Salles, C. O. Pereira, P. C. M. Meira, and W. Freitas, "A Comprehensive Assessment of PV Hosting Capacity on Low-Voltage Distribution Systems," IEEE Trans. Power Deliv., vol. 33, no. 2, pp. 1002-1012, 2018. https://doi.org/10.1109/TPWRD.2018.2798707

[12] H. Al-Saadi, R. Zivanovic, and S. F. Al-Sarawi, "Probabilistic Hosting Capacity for Active Distribution Networks," IEEE Trans. Ind. Informatics, vol. 13, no. 5, pp. 2519-2532, 2017. https://doi.org/10.1109/TII.2017.2698505

[13] J. Zhao, J. Wang, Z. Xu, C. Wang, C. Wan, and C. Chen, "Distribution Network Electric Vehicle Hosting Capacity Maximization: A Chargeable Region Optimization Model," IEEE Trans. Power Syst., vol. 32, no. 5, pp. 4119-4130, 2017. https://doi.org/10.1109/TPWRS.2017.2652485

[14] A. Kulmala, S. Repo, and J. Pylvänäinen, "Generation curtailment as a means to increase the wind power hosting capacity of a real regional distribution network," CIRED - Open Access Proc. J., vol. 2017, no. 1, pp. 1782-1786, 2017. https://doi.org/10.1049/oap-cired.2017.0925

[15] P. Saxena and A. Kothari, "Ant Lion Optimization algorithm to control side lobe level and null depths in linear antenna arrays," AEU - Int. J. Electron. Commun., vol. 70, no. 9, pp. 1339-1349, 2016. https://doi.org/10.1016/j.aeue.2016.07.008

[16] S. P. Santosa, Dian Budi; Sardjiya, Hadi, "Algoritma Aliran DAya dengan Metode Backward/Forward Sweep pada Sistem Distribusi Radial,” ISBN 2085-6350, pp. 78-82, 2017.

[17] E. S. Ali, S. M. Abd Elazim, and A. Y. Abdelaziz, "Ant Lion Optimization Algorithm for renewable Distributed Generations," Energy, vol. 116, pp. 445-458, 2016. https://doi.org/10.1016/j.energy.2016.09.104

[18] E. S. Ali, S. M. Abd Elazim, and A. Y. Abdelaziz, "Ant Lion Optimization Algorithm for optimal location and sizing of renewable distributed generations," Renew. Energy, vol. 101, pp. 1311-1324, 2017. https://doi.org/10.1016/j.renene.2016.09.023

[19] S. Shaddiq "Peningkatan Keandalan Sistem Distribusi dengan Penempatan Optimal Wind-based Distributed Generation menggunakan Metode Flower Pollination Algorithm," Thesis Universitas Gadjah Mada, 2017.

[20] M. J. Hadidian-moghaddam, S. Arabi-nowdeh, M. Bigdeli, and D. Azizian, "A multi-objective optimal sizing and siting of distributed generation using ant lion optimization technique," Ain Shams Eng. J., vol. 9, no. 4, pp. 21012109, 2018. https://doi.org/10.1016/j.asej.2017.03.001

[21] M. H. Moradi and M. Abedini, "A combination of genetic algorithm and particle swarm optimization for optimal DG location and sizing in distribution systems," Int. J. Electr. Power Energy Syst., vol. 34, no. 1, pp. 66-74, 2012. https://doi.org/10.1016/j.ijepes.2011.08.023

\section{BIOGRAPHY OF AUTHORS}

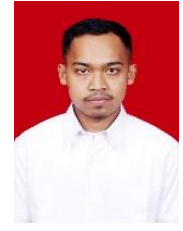

Riki Khomarudin was received A.Md degree in Electrical Engineering Technology from Universitas Gadjah Mada, in 2018. He received hi S.T. degree in Electrical Engineering Department from Universitas Muhammadiyah Yogyakarta in 2019. He is currently studying Master of Engineering (M.T) at Institut Teknologi Bandung. His research interest in power systems. Email: riki.khomarudin@mail.ugm.ac.id 


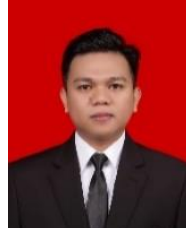

Jimmy Trio Putra received the B.Eng. degree from the University of Bengkulu, Bengkulu, Indonesia, in 2013, and M.Eng. degree from Universitas Gadjah mada, Yogyakarta, Indonesia, in 2015, both in electrical engineering. He has been with the Departement of Electrical Engineering and Informatics, Vocational College, Universitas Gadjah Mada, since 2016. His research interest includes power system operation and control and renewable energy and optimization. Email: jimmytrioputra@ugm.ac.id

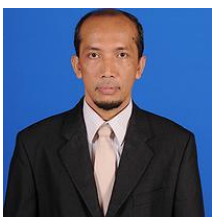

Ramadoni Syahputra received B.Sc. degree from Institut Teknologi Medan in 1998, M.Eng. degree from Department of Electrical Engineering, Universitas Gadjah Mada, Yogyakarta, Indonesia in 2002, and Ph. D degree at the Department of Electrical Engineering, Faculty of Industrial Technology, Institut Teknologi Sepuluh Nopember, Surabaya, Indonesia in 2015. Dr. Ramadoni Syahputra is a Lecturer in the Department of Electrical Engineering, Faculty of Engineering, Universitas Muhammadiyah Yogyakarta, Indonesia. His research interests are in computational power systems, artificial intelligence in power systems, power system control, the application of fuzzy logic in power systems, optimization, distributed energy resources, and renewable energy. Email: ramadoni@umy.ac.id

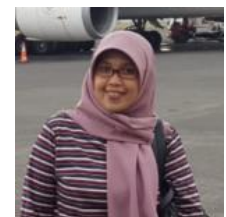

Anna Nur Nazilah Chamim obtained her B.Eng. in Electrical Engineering from Universitas Muhammadiyah Yogyakarta, Indonesia. Her Master study was done at 2015 at the Electrical Engineering, Universitas Gadjah Mada, Indonesia. She currently is a lecture in department of electrical engineering, Universitas Muhammadiyah Yogyakarta. Email: anna_nnc@umy.ac.id 